\title{
Internet Connection

\section{Chemshow}

D) rofessors Emeriti of Chemistry Rubin Battino and John J. Fortman of Wright State University in Dayton, Ohio, USA, have been doing chemistry demonstration shows for middle and high school students for about 35 years. They estimate that over one quarter of one million students have seen the live shows. Currently, they do 19 of these free shows each year.

During winter and spring breaks, Battino and Fortman entertain and teach middle and high school students about the wonderful world of chemistry. Now students anywhere can watch these performances at <www.wright.edu/ctl/eventstream/ ondemand.html>. A show from 12 December 2008 can be viewed by clicking on the highlights button and then selecting Chemistry Demonstration Show from the menu.

Don't try this at home kids.

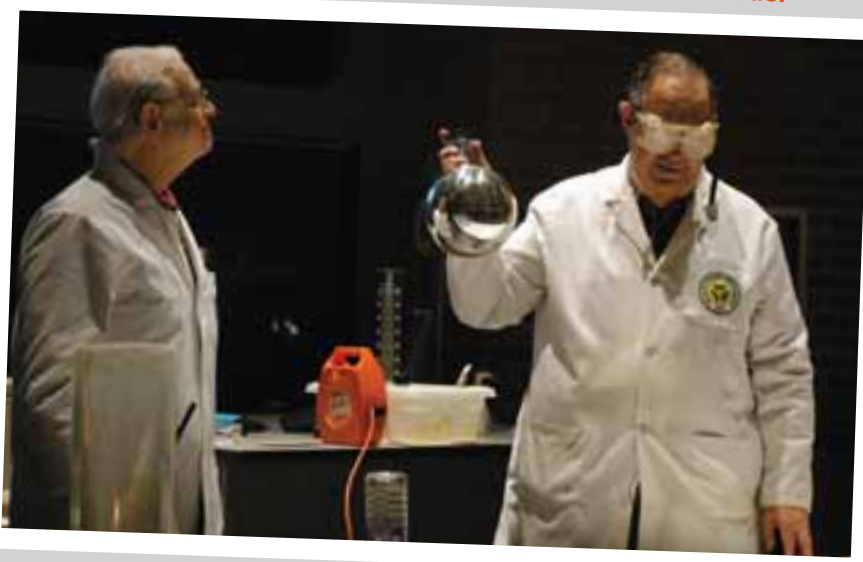

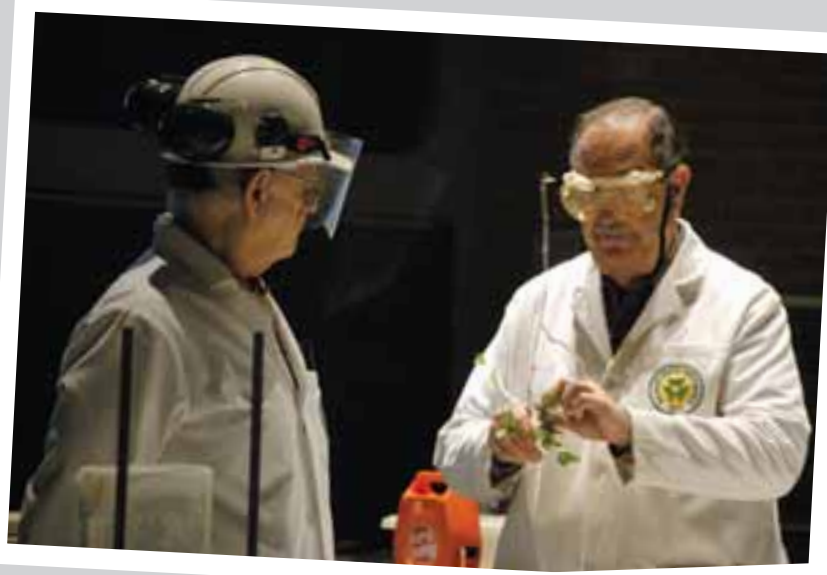

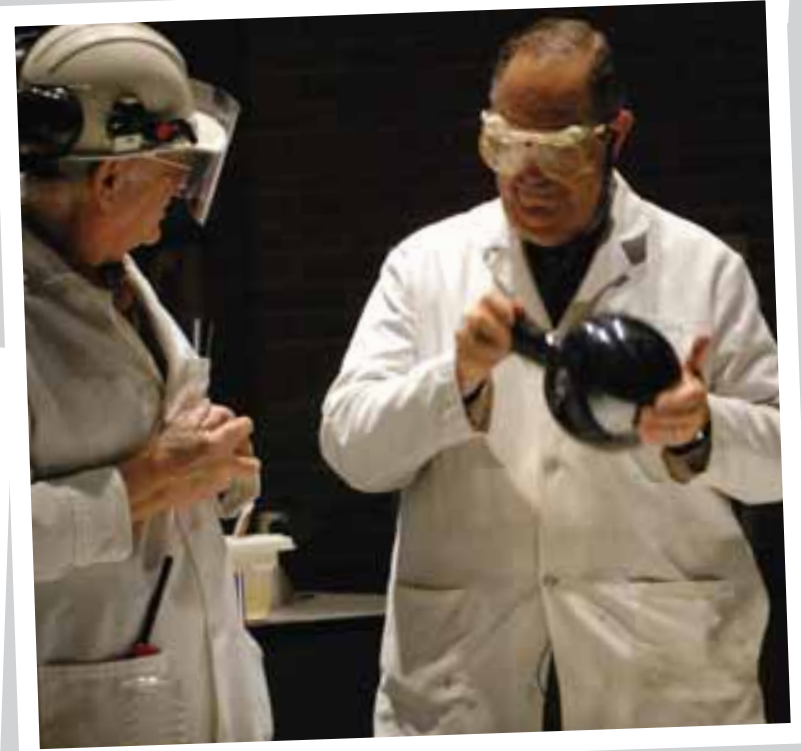

Professors Emeriti of Chemistry Rubin Battino and John Fortman of Wright State University in Dayton, ohio, USA, at a recent chemistry demonstration.

Sim. www.wright.edu/ctl/eventstream/ondemand.html

\section{RSClate-}

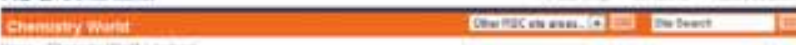

chemistryinitselement

ชิำ

(U)

Na 2 बas

2010

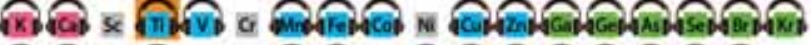

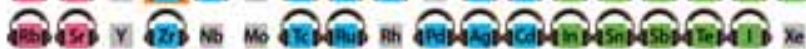
क्रि०

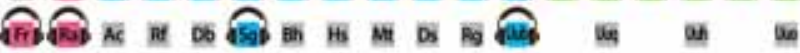
ใคำ मां

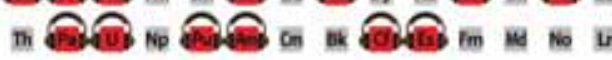

\section{Element podcast}

Chemistry World takes a whirlwind tour of the periodic table: each week a leading scientist or author tells the story behind a different element.

Iii. www.rsc.org/chemistryworld/podcast/element.asp 